\title{
CLINICAL, HAEMATOLOGICAL AND BLOOD BIOCHEMICAL CHANGES IN GOATS AFTER EXPERIMENTAL INFECTION WITH TICK-BORNE FEVER
}

\author{
A.S.J.P.A.M. VAN MIERT ${ }^{1}$, C.T.M. VAN DUIN ${ }^{1}$, A.J.H. SCHOTMAN ${ }^{2}$ and \\ F.F. FRANSSEN ${ }^{3}$ \\ 'Department of Veterinary Pharmacology, Pharmacy and Toxicology, Faculty of Veter- \\ inary Medicine, University of Utrecht, P.O. Box 80.176, 3508 TD Utrecht (The Nether- \\ lands) \\ ${ }^{2}$ Department of Large Animal Medicine, Yalelaan 16, Utrecht (The Netherlands) \\ ${ }^{3}$ Department of Tropical Veterinary Medicine and Protozoology, P.O. Box 80.172, \\ 3508 TD Utrecht (The Netherlands)
}

(Accepted for publication 8 May 1984)

\begin{abstract}
Van Miert, A.S.J.P.A.M., van Duin, C.T.M., Schotman, A.J.H. and Franssen, F.F., 1984. Clinical, haematological and blood biochemical changes in goats after experimental infection with tick-borne fever. Vet. Parasitol., 16: 225--233.

Tick-borne fever in goats caused by Ehrlichia (Cytoecetes) phagocytophila was characterised by high fever, dullness, anorexia, tachycardia and a slight to moderate inhibition of rumen motility. The animals developed a gradual decline in the total number of circulating white blood cells. There was a decrease in lymphocytes over a short period, followed by an increase. The number of neutrophils was higher on the 3rd day, causing considerable change in the lymphocyte:neutrophil ratios. The number of eosinophils increased slightly. Serum alkaline phosphatase (ALP) decreased during the febrile episodes, and a marked decline was observed in both plasma zinc and iron concentrations. Furthermore, there was a small but progressive decrease of haemoglobin and haematocrit values. Circulating endogenous pyrogen/leucocyte endogenous mediator could not be detected in plasma from febrile goats. Tick-borne fever was passively transmitted to kids with plasma obtained from these febrile animals.
\end{abstract}

\section{INTRODUCTION}

Tick-borne fever (TBF) is a rickettsial disease of ruminants characterised by high fever and severe leucopaenia (Venn and Woodford, 1'156; Tuomi, 1967; Woldehiwet, 1983). Concurrently with the temperature rise, most animals are slightly to moderately depressed, have diminished appetite and rumination is absent. In cows the pulse rate is only slightly elevated during the febrile episodes, whereas mild coughing can be seen after fever has subsided (Tuomi, 1976). Milk yield is reduced to half the normal amount or less (Venn and Woodford, 1956; Bool and Reinders, 1964; Tuomi, 1967). 
Complications following TBF infection include abortion in ewes and cows (Stamp and Watt, 1950; Venn and Woodford, 1956; Wilson et al., 1964). Adult animals seem to be affected more markedly than neonates, although neonates exhibit a definite reaction (Tuomi, 1967). The disease is caused by Ehrlichia (Cytoecetes) phagocytophila, which invades neutrophils, but monocytes are infected to a lesser degree (Woldehiwet, 1983). Characteristic TBF-inclusion bodies can be found in the peripheral neutrophils during febrile episodes.

It is generally believed that fever is mediated by endogenous pyrogens (EP), proteins which are produced by activated neutrophils, monocytes and other phagocytic cells and act on CNS temperature regulating centres ( $\mathrm{Di}$ narello, 1980; Milton, 1982). Leucocyte endogenous mediator (LEM), which also is produced by activated neutrophils, is the causative agent for the decrease in the plasma concentrations of zinc and iron during both infection (Beisel, 1976, 1977) and endotoxinaemia (Kampschmidt and Upchurch, 1962; Pekarek and Beisel, 1971; Groothuis et al., 1981; Verheijden et al., 1982; van Miert et al., 1982, 1983b). The purpose of the present study was to identify any alteration in clinical, haematological and blood biochemical values during fever caused by Ehrlichia (Cytoecetes) phagocytophila in goats and to detect circulating EP/LEM in plasma from the infected animals.

\section{MATERIALS AND METHODS}

\section{Animals}

Six clinically healthy dwarf goats (females and castrated males) were inoculated with E. phagocytophila. They weighed between 27 and $50 \mathrm{~kg}$. Foux kids, 16 and 21 days old, weighing between 3.1 and $3.5 \mathrm{~kg}$ were also used. All animals were kept indoors and fed a diet of hay and pelleted concentrate. Water was provided ad lib.

\section{Infection}

Ehrlichia (Cytoecetes) phagocytophila isolated from sheep at Ameland, The Netherlands, was used. It was inoculated intravenously into a spleenectomised sheep using $150 \mathrm{ml}$ of pooled EDTA blood from 23 donor sheep. Three days after inoculation when blood smears from this animal were positive for presence of $E$. phagocytophila, blood samples were taken from the jugular vein and frozen after addition of DMSO to a final concentration of $9 \%$. In the present experiments, the goats were infected by i.v. inoculation of $2 \mathrm{ml}$ of the stabilate. Blood samples from 4 infected goats were collected in Vacutainer tubes (VenojectR, Terumo, Tokyo, Japan). These samples were used for blood biochemical and haematological analysis. Plasma samples obtained from heparinised blood from the 2 other infected goats were 
assayed in kids for EP/LEM activity (Van Miert and Atmakusuma, 1970). Fifteen $\mathrm{ml} \mathrm{kg}^{-1}$ of plasma was administered intravenously to these kids.

\section{Clinical signs}

Before the experiments the goats were trained to stand quietly by repeatedly placing them in the experimental cage for several hours at a time, after passing nasal catheters to the rumen. Procedures for recording rumen contractions, heart rate and rectal temperature were the same as those described previously (Van Miert et al., 1977; Veenendaal et al., 1976). The frequency (RF) and amplitude (RA) of the rumen contractions were determined once every $15 \mathrm{~min}$ and expressed in percentages of the preinjection value.

\section{Blood biochemical and haematological analysis}

Alkaline phosphatase (ALP), plasma iron and zinc concentrations, total cell counts, haemoglobin, haematocrit and differential WBC counts were determined, using methods described previously (Van Miert et al., 1982 and $1983 \mathrm{~b}$ ). During the course of infection blood samples were examined for TBF-inclusion bodies in the neutrophils using Giemsa-stained smears and the morphological criteria of Woldehiwet and Scott (1982).

\section{Statistical analysis}

Results were expressed as mean \pm SEM. The paired $t$ test was used to compare the baseline and later values from the same group of animals.

\section{RESULTS}

The mean rectal temperature in the goats and the kids before they were infected was 38.5 and $39.45^{\circ} \mathrm{C}$, respectively. In the goats the mean frequency of the heart beat was $90 / \mathrm{min}$, whereas the rumen contractions occurred approximately once a minute. The base-line values of the blood biochemical and haematological determinations are shown in Tables I and II. In the TABLE I

Haematological values in goats during tick-borne fever

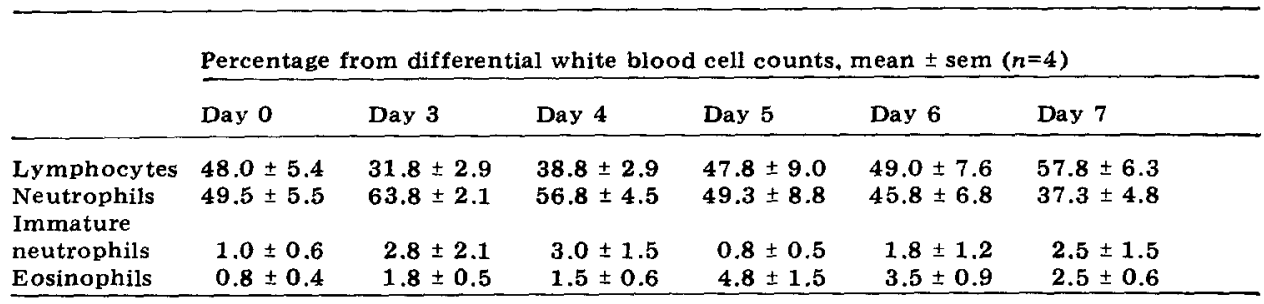


Blood cells and biochemical values in goats during tick-borne fever

\begin{tabular}{|c|c|c|c|c|c|c|c|}
\hline & \multirow[b]{2}{*}{$\begin{array}{l}\text { Day } 0 \text { (base- } \\
\text { line) }\end{array}$} & \multicolumn{6}{|c|}{ Percentage from base-line after infection, mean $\pm \operatorname{SEM}(n=4)$} \\
\hline & & Day 3 & Day 4 & Day 5 & Day 6 & & Day 7 \\
\hline $\begin{array}{l}\text { WBC (base-line } \\
\text { in (Giga } \mathrm{1}^{-1} \text { ) }\end{array}$ & $11.89 \pm 0.78$ & $76.1 \pm 12.4$ & $53.5 \pm 6.3$ & $28.6 \pm 3.3$ & $29.6 \pm$ & 6.5 & $27.1 \pm 4.6$ \\
\hline $\begin{array}{l}\text { Haemoglobin (base- } \\
\text { line in } \mathrm{mmol}^{-1} \text { ) }\end{array}$ & $6.29 \pm$ & $84.8 \pm 3.1$ & $87.9 \pm 2.2$ & $87.3 \pm 5.5$ & $86.1 \pm$ & 6.1 & $81.3 \pm 6.5$ \\
\hline $\begin{array}{l}\text { Haematocrit (base- } \\
\text { line in } 11^{-1} \text { ) }\end{array}$ & $0.30 \pm$ & $89.4 \pm 6.0$ & $91.0 \pm 3.5$ & $93.7 \pm 6.2$ & $86.2 \pm$ & 7.6 & $82.8 \pm 6.8$ \\
\hline $\begin{array}{l}\text { ALP (base-line } \\
\text { in I.U. } 1^{-1} \text { ) }\end{array}$ & $112.3 \pm 17.2$ & $67.8 \pm 6.9$ & $54.4 \pm 7.9$ & $48.1 \pm 9.9$ & $38.8 \pm$ & 3.6 & $42.5 \pm 6.1$ \\
\hline $\begin{array}{l}\text { Iron (base-line } \\
\text { in } \mu \mathrm{mol} \mathrm{l}^{-1} \text { ) }\end{array}$ & $24.88 \pm$ & $50.5 \pm 7.9$ & $38.4 \pm 4.1$ & $42.2 \pm 2.0$ & $62.8 \pm$ & 4.9 & $88.9 \pm 14.4$ \\
\hline $\begin{array}{l}\text { Zine (base-line } \\
\text { in } \mu \mathrm{mol}^{-1} \text { ) }\end{array}$ & $9.9 \pm$ & $40.9 \pm 10.4$ & $51.6 \pm 8.2$ & $77.8 \pm 11.2$ & $97.3 \pm 1$ & 13.6 & $94.8 \pm 10.6$ \\
\hline
\end{tabular}

kids the pre-infection values of the plasma zinc and iron concentrations were $15.8 \mu \mathrm{mol} \mathrm{l}^{-1}$ and $23.7 \mu \mathrm{mol} \mathrm{l}^{-1}$ respectively.

After inoculation, the characteristic inclusions of TBF were observed from the 3rd to the 8th day, but were most prominent in the neutrophils on the 3rd or 4th day of infection. After a sudden rectal temperature rise on the 3rd day of infection, a plateau of $40-41^{\circ} \mathrm{C}$ was maintained over a period of 3-6 days, followed by a rapid fall to normal body temperature (Fig. 1). Concurrently, the heart rate was elevated with maximum values on the 3rd day. However, the increase in heart rate could not be positively correlated with the change in body temperature (Fig. 1). The rumen contractions were slightly to moderately depressed, despite high rectal temperatures (Fig. 1 and Fig. 2). Moreover, short periods ( $<10 \mathrm{~min}$ ) of rumination were observed in all goats on the $3 \mathrm{rd}$, 4th and 5th day post-infection. Other symptoms observed were anorexia, dullness and periods of shivering.

The infected goats had a gradual decline in the number of circulating white blood cells (Table II). There was a decrease in lymphocytes over a short period, which was followed by an increase (Table I). The number of neutrophils was higher on the 3rd day, causing considerable changes in the lymphocyte:neutrophil ratios. This was also observed on the 7th day, but it was the result of a higher number of lymphocytes. No marked shift to less mature neutrophils was seen during the observation period. A marked increase in the number of eosinophils was seen on the 5th day followed by a gradual decline (Table I). Serum ALP activity decreased significantly $(P<0.001)$ during the febrile episodes (Table II). Furthermore, there was a small but progressive decrease of haemoglobin and haematocrit values. A marked decline was seen in the plasma zinc concentrations to the lowest values on the 3rd day, but they then rose to normal (Table II). The decrease 


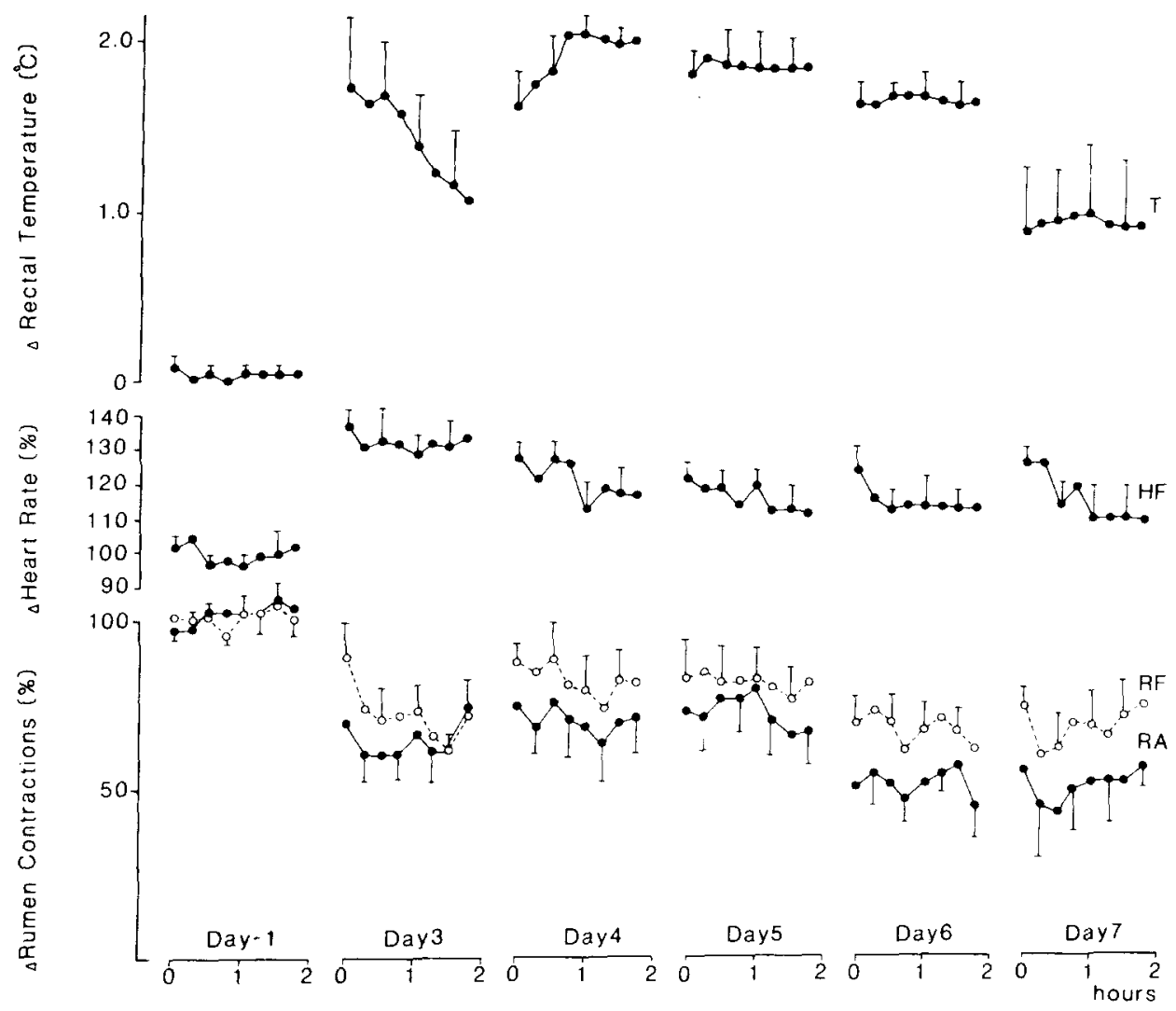

Fig. 1. Changes in rectal temperature, heart rate and rumen motility in goats $(n=4)$ during the course of $E$. phagocy tophila infection. $T=$ change in body temperature $(0=$ base-line: $38.5 \pm 0.04^{\circ} \mathrm{C}$ ); $H F=$ frequency of heart beat $\mathrm{min}^{-1}$ expressed in percentage of the base-line value $(90 \pm 2.9$ per minute). Rumen contractions are expressed in percentages of the pre-infection values; $R F=$ frequency of contractions per $15 \mathrm{~min} ; R A=$ summation derived from $15 \mathrm{~min}$ intervals of amplitude. Values are given as mean $\pm S E M$ (bars above and below dots).

in plasma iron concentrations to their lowest values on the 4th day, was more persistent (Table II).

The plasma obtained from febrile goats did not cause fever in the recipient kids. Moreover, no significant changes were observed in plasma zinc $\left(16.8 \mu \mathrm{mol} \mathrm{l}^{-1}\right)$ and plasma iron $\left(23.7 \mu \mathrm{mol} \mathrm{l}^{-1}\right)$ concentrations $4 \mathrm{~h}$ after injection of donor-plasma. These results demonstrate that circulating EP/LEM could not be detected in plasma from febrile goats infected with $E$. phagocytophila. However, on the 3rd day post-inoculation with plasma from febrile goats, the kids showed a rise in rectal temperature $\left(41.5^{\circ} \mathrm{C}\right)$ accompanied by sedation, piloerection, drooping of the ears and shivering. These kids assumed a "bended back" position. Characteristic TBF-inclusion bodies were found in the circulating neutrophils. Plasma zinc $\left(10.0 \mu \mathrm{mol} \mathrm{l}^{-1}\right)$ and iron $\left(14.5 \mu \mathrm{mol} \mathrm{l}^{-1}\right)$ levels were significantly. depressed. 

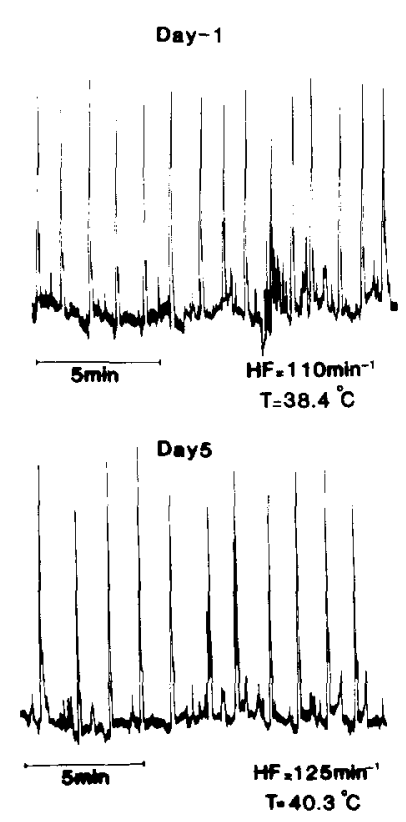

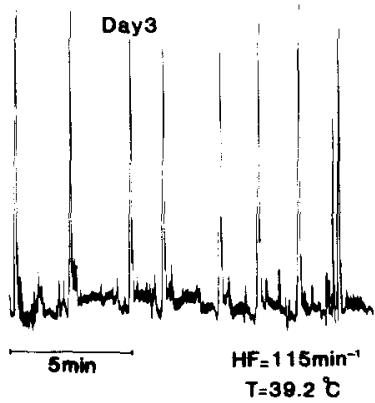

Day6

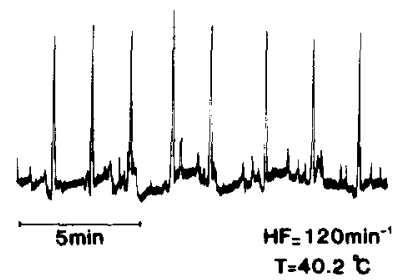

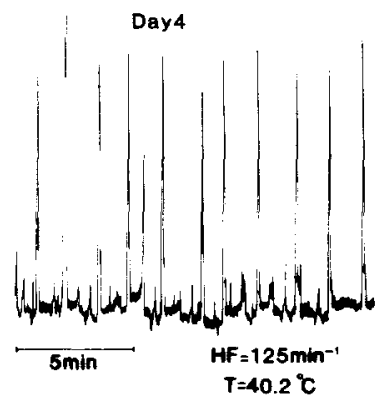

Day 7

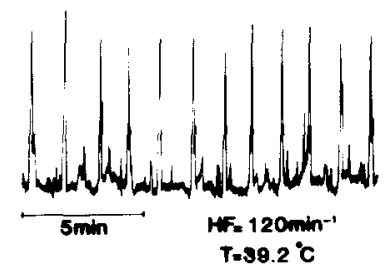

Fig. 2. Changes of rumen contractions in 1 goat during the course of $E$. phagocy tophila infection. $H F=$ frequency of heart beat $\min ^{-1} ; T=$ rectal temperature in ${ }^{\circ} \mathrm{C}$.

At the end of the experiments, goats and kids were intramuscularly injected with oxytetracycline $\left(20 \mathrm{mg} \mathrm{kg}{ }^{-1}\right)$. All clinical signs disappeared within $12 \mathrm{~h}$ and no relapses were seen during the following 6 weeks.

\section{DISCUSSION}

Tick-borne fever in goats was characterised by high fever, tachycardia and a slight to moderate inhibition of rumen contractions. Heart rate was elevated with maximum values 3 days after infection. It has been suggested that there is a good correlation between the increase in heart rate and the rise in body temperature during febrile episodes (Cooper, 1971). In the present experiments, however, we did not find such a correlation between these 2 parameters.

During the febrile episodes the organisms were detected in large numbers in the neutrophils, whereas monocytes were infected to a lesser degree. Similar observations were described by other investigators using sheep or cows (see review Woldehiwet, 1983). In vitro, activated neutrophils and monocytes produce both endogenous pyrogens (EP) and leucocyte endogenous mediator (LEM). LEM is the causative agent for the decreases in the plasma concentrations of zinc and iron during fever (Beisel, 1976, 1977; van Miert et al., 1983b). Therefore, we could expect changes in plasma zinc and iron concentrations in TBF-infected goats. There was 
a marked decline in plasma zinc to nadir values on the 3rd day; plasma concentrations then rose to become as much as those in the pre-infection period. The decrease in plasma iron concentrations was more persistent in these goats, which suggests that plasma zinc and iron do not behave in a similar way. One mechanism accounting for at least part of the acute lowering of the plasma concentrations of both trace elements is uptake by the liver (Beisel, 1976, 1977). Contrary to the previously documented data for neonatal and adult guinea pigs (Blatteis et al., 1981), kids have significantly higher plasma zinc levels than adult goats $(P<0.001)$. EP is generally thought to be the final common pathway in many experimental fevers, and there is evidence that these pyrogens act on thermoregulatory centres through the stimulation of prostaglandin $\mathrm{E}_{2}$ synthesis (Ziel and Krupp, 1976; Milton, 1982). Circulating EP has repeatedly been demonstrated in plasma from goats (Van Miert and Atmakusuma, 1970; Verheijden et al., 1983) and other species (Gander, 1982) during fever induced by i.v. injection of bacterial pyrogens. In the present study, circulating EP/LEM could not be detected in plasma from febrile goats infected with $E$. phagocytophila.

The most likely explanation for this discrepancy in results involves the hypothesis of a low but constant release of EP/LEM into plasma from infected animals in contrast to peak concentrations of EP/LEM after a single bolus injection of bacterial pyrogens. The value of the bioassay technique used is limited due to volume limitations of the dose to be administered. Moreover, EP is cleared rapidly from the blood (Dinarello et al., 1978). This explains why circulating EP/LEM has yet to be convincingly demonstrated during febrile infectious diseases.

In goats intracerebroventricular injection of $\mathrm{PGE}_{2}$ caused shivering, a sharp increase in body temperature and a moderate inhibition of rumen motility (Van Miert et al., 1983a). Moreover, antipyretic agents (which inhibit synthesis of prostaglandins) significantly reduced the inhibition of rumen contractions due to bacterial pyrogens (Van Miert et al., 1977, 1982). Therefore, it seems likely that the diminished forestomach motility observed during febrile episodes in TBF goats, is partly due to a release of $\mathrm{PGE}_{2}$.

TBF was passively transmitted to kids with plasma obtained from febrile goats. After a latency period of 3 days the kids reacted with high fever associated with significantly lower plasma zinc and iron levels, whereas blood smears showed the typical TBF inclusion bodies in the neutrophils. These results show that kids are very susceptible to $E$. phagocytophila infections.

TBF caused a fall in serum ALP activity in adult goats. Likewise, hypozincaemia, hypoferraemia and a fall in serum ALP activity were found in goats treated with bacterial pyrogens (Van Miert et al., 1983b). Kincaid et al. (1976) suggested a relationship between serum ALP activity and plasma zinc concentration. However, such a correlation could not be found in our studies (see also Table I and II). Furthermore, there was a small, 
but progressive diminution of haemoglobin and haematocrit values in TBFinfected goats. Similar observations were described by other investigators using sheep (Taylor et al., 1941) or cows (Tuomi, 1967). In principle, the changes in total white blood cell counts and in differential white blood cell counts were as reported by others (Taylor et al., 1941; Tuomi, 1967; Woldehiwet, 1983).

\section{REFERENCES}

Beisel, W.R., 1976. Trace elements in infectious processes. Med. Clin. North Am., 60: 831-849.

Beisel, W.R., 1977. Zinc metabolism in infection. In: Zinc Metabolism: Current Aspects in Health and Diseases. Alan R. Liss, New York, pp. 155-176.

Blatteis, C.M., Mashburn, T.A. and Ahokas, R.A., 1981. Fever and trace metal changes in endotoxin-challenged neonates. Pflügers Arch. Eur. J. Physiol., 389: 177-179.

Bool, P.H. and Reinders, J.S., 1964. Tick-born fever in bovines in the Netherlands. Tijdschr. Diergeneeskd., 89: 1519-1527.

Cooper, K.E., 1971. Some physiological and clinical aspects of pyrogens. In: G.E.W. Wolstenholme and J. Birch (Editors), Pyrogens and Fever. Churchill-Livingstone, Edinburgh-London, pp. 5-21.

Dinarello, C.A., 1980. Endogenous pyrogens. In: J.M. Lipton (Editor), Fever. Raven Press, New York, pp. 1-9.

Dinarello, C.A., Weiner, P. and Wolff, S.M., 1978. Radiolabel and disposition in rabbits of purified human leukocytic pyrogen. Clin. Res., 26: 522A.

Gander, G.W., 1982. Endogenous pyrogens In: A.S. Milton (Editor), Pyretics and Antipyretics. Handbook of Experimental Pharmacology, Springer-Verlag, 60: 113-123.

Groothuis, D.G., Van Miert, A.S.J.P.A.M. and Schotman, A.J.H., 1981. Zinc concentration in plasma during experimental Salmonella dublin infection and endotoxin induced fever in calves. Vet. Rec., 109: 176-177.

Kampschmidt, R.F. and Upchurch, H., 1962. Effects of bacterial endotoxin on plasma iron. Proc. Soc. Exp. Biol, Med., 110: 191-193.

Kincaid, R.L., Miller, W.J., Gentry, R.P., Neathery, M.W., Hampton, D.L. and Lassiter, J.W., 1976. The effect of endotoxin upon zinc retention and intracellular liver distribution in rats. Nutr. Rep. Int., 13: 65-70.

Milton, A.S., 1982. Prostaglandins and fever. Trends Pharmacol. Sci., 3: 490-492.

Pekarek, R.S. and Beisel, W.R., 1971. Characterization of the endogenous mediator(s) of serum zinc and iron depression during infection and other stresses. Proc. Soc. Exp. Biol. Med., 138: 728-732.

Stamp, J.T. and Watt, J.A., 1950. Tick-borne fever as a cause of abortion in sheep. Part I. Vet. Rec., 62: 465-468.

Taylor, A.W., Holman, H.H. and Gordon, W.S., 1941. Attempts to reproduce the pyaemia associated with tick-bite. Vet. Rec., 53: 339-344.

Tuomi, J., 1967. Experimental studies on bovine tick-borne fever (1) Clinical and haematological data, some properties of the causative agent and homologous immunity. Acta Pathol. Microbiol. Scand., 70: 429-445.

Van Miert, A.S.J.P.A.M. and Atmakusuma, A., 1970. Comparative observations on the production of fever by bacterial pyrogens and leucocytic pyrogen in goats and rabbits. Zentralbl. Veterinaermed., A17: 174-184.

Van Miert, A.S.J.P.A.M., Van der Wal-Komproe, L.E. and Van Duin, C.T.M., 1977. Effects of antipyretic agents on fever and ruminal stasis induced by endotoxins in conscious goats. Arch. Int. Pharmacodyn. Ther., 225: 39-50. 
Van Miert, A.S.J.P.A.M., Van Duin, C.T.M., Verheijden, J.H.M. and Schotman, A.J.H., 1982. Endotoxin-induced fever and associated haematological and blood biochemical changes in the goat: The effect of repeated administration and the influence of flurbiprofen. Res. Vet. Sci., 33: 248-255.

Van Miert, A.S.J.P.A.M., van Duin, C.T.M. and Woutersen-Van Nijnanten, F.M.A., 1983a. Effect of intracerebroventricular injection of $\mathrm{PGE}_{2}$ and 5-HT on body temperature, heart rate and rumen motility of conscious goats. Eur. J. Pharmacol., 92: $143-146$.

Van Miert, A.S.J.P.A.M., Van Duin, C.T.M., Verheijden, J.H.M. and Schotman, A.J.H., 1983b. Staphylococcal enterotoxin B and Escherichia coli endotoxin: Comparative observations in goats on fever and associated clinical hematologic and blood biochemical changes after intravenous and intramammary administration. Am. J. Vet. Res., 44: 955-963.

Veenendaal, G.H., Van Miert, A.S.J.P.A.M., Van den Ingh, T.S.G.A.M., Schotman, A.J.H. and $Z$ wart, D., 1976. A comparison of the role of kinins and serotonin in endotoxin induced fever and Trypanosoma vivax infections in the goat. Res. Vet. Sci., 21: 271-279.

Venn, J.A.J. and Woodford, M.H., 1956. An outbreak of tick-borne fever in bovines. Vet. Rec., 68: 132-133.

Verheijden, J.H.M., van Miert, A.S.J.P.A.M., Schotman, A.J.H. and Van Duin, C.T.M., 1982. Plasma zinc and iron concentrations as measurements for evaluating the influence of endotoxin-neutralizing agents in Escherichia coli endotoxin-induced mastitis. Am. J. Vet. Res., 43: 724-728.

Verheijden, J.H.M., van Miert, A.S.J.P.A.M. and Van Duin, C.T.M., 1983. Demonstration of circulating endogenous pyrogens in Escherichia coli endotoxin-induced mastitis. Zentralbl. Veterinaermed., A30: 342-347.

Wilson, J.E., Foggie, A. and Carmichael, M.A., 1964. Tick-borne fever as a cause of abortion and still-births in cattle. Vet. Rec., 76: 1081-1084.

Woldehiwet, Z., 1983. Tick-borne fever: a review. Vet. Res. Commun., 6: 163-175.

Woldehiwet, Z. and Scott, G.R., 1982. Immunological studies on tick-borne fever in sheep. J. Comp. Pathol., 92: 457-467.

Ziel, R. and Krupp, P., 1976. Influence of endogenous pyrogen on the cerebral prostaglandin-synthetase system. Experientia, 32: 1451-1452. 